\section{Mediterranean pollution: one man's optimism}

The 1978 Monaco meeting of the 17 Mediterranean countries involved in the 'Mediterranean Action Plan' to clean up pollution closed last Saturday to such headlines as 'Deadlock over Med' and 'Pollution talks go into stagnation'. But in Geneva, the headquarters of the United Nations Environment Project's 'Regional Seas' programme, one man remains unrepentantly optimistic: the director of the programme, and inspiration of the Mediterranean Action Plan, Dr Stjepan Keckes.

Dr Keckes (his name is pronounced 'Keshkesh') is almost literally the power behind the Mediterranean plan. A 46year-old marine scientist, member of the Hungarian minority of Yugoslavia, he has in 4 years established a ring of 79 cooperating research centres (some of them in perpetually antagonistic states such as Greece and Turkey, Egypt and (srael) and produced a baseline study of Mediterranean pollution which all governments respect-no mean achievement.

And with his principal colleagues Patricia Bliss (legal adviser) and Mohammed Tangi (environmental management) Keckes has been responsible for a sequence of inter-governmental agreements on pollution which, despite Monaco, has been one of the jewels in the UN's crown. Next month the first of two protocols to control dumping and environmental accidents come into force, ratified by six Mediterranean states (Spain, France, Yugoslavia, Tunisia, Lebanon and Monaco). Few international agreements move so fast: only $10 \%$ of the signatories to the 1973 London Dumping Convention, for

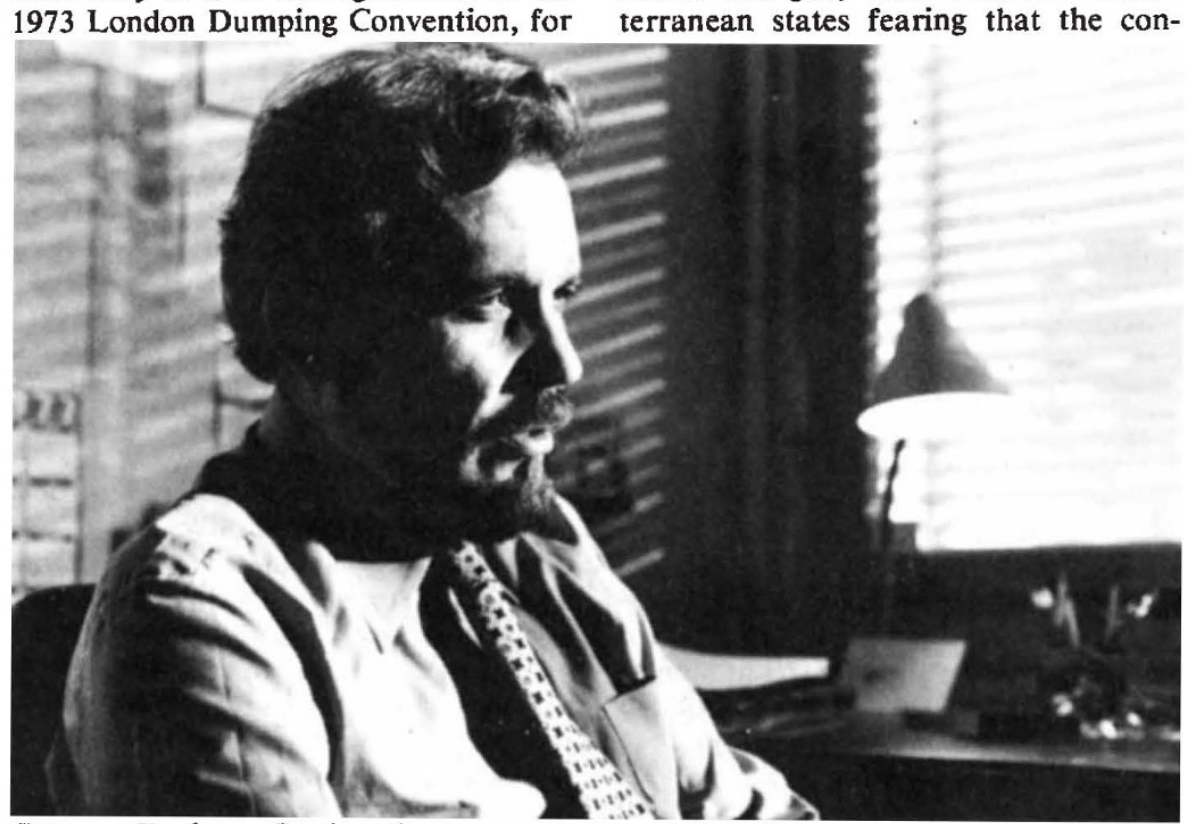

Stjepan Keckes: Confronting governments with reality example, have ratified the Convention. Keckes can claim $33 \%$ in two years for the protocols of the 1976 Barcelona Convention on Mediterranean pollution. Keckes has a right to be optimistic.

Speaking this week from Geneva Keckes told Nature that he was "perfectly satisfied" with the meeting in Monaco, and that it had "fulfilled our expectations completely". That cannot be entirely accurate, however, for Keckes, interviewed by Nature in December, spoke of the Monaco meeting paving the way for the adoption of a third protocol-the one that bites, on land-based sources, which deliver $80 \%$ of the pollution load- "by the autumn" of 1978. At Monaco, however, there was little progress on the protocol and a further discussion session has been planned for Geneva in Octoberto be followed by a meeting in Athens to adopt the protocol at no specified date. Keckes, ever optimistic, is delighted that at least the place for the adoption of the protocol-Athens-has been decided.

The third protocol defines a 'black list' of substances that must on no account be released to the Mediterranean, and a 'grey list' which can be released but only in certain limited amounts. The governments involved have estimated that to implement the necessary controls would cost some $\$ 10$ billion in initial capital investment, a large part of it to control the industrial pollution flowing from the rivers Rhone (France) and Po (Italy). Difficulties have arisen over the NorthSouth dialogue, with Southern Mediterranean states fearing that the con-

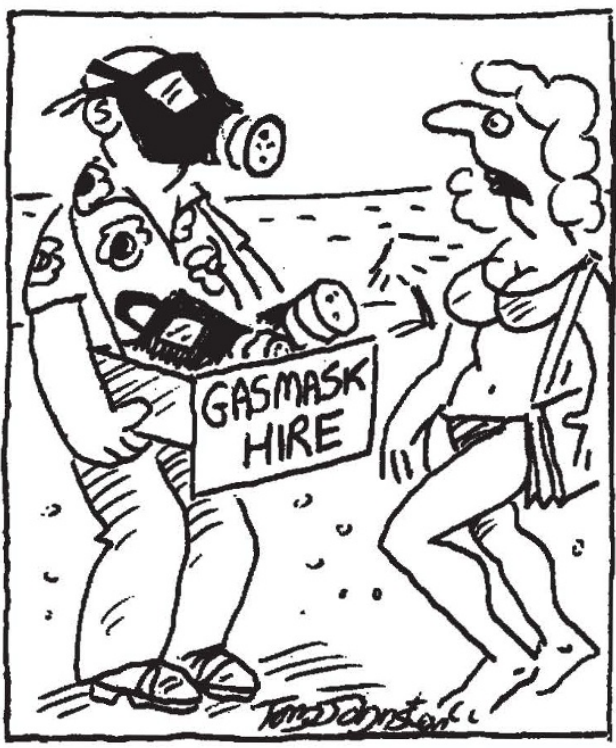

trols will inhibit their industrial development; and over whether the countries responsible for most of the pollution should pay compensation to the other states; and over the control of pollution in rivers.

Keckes remains satisfied that these difficulties will be solved, while recognising that agreeing the third protocol will be "the most difficult thing Mediterranean states will ever negotiate. We are not rushing them".

There were successes at Monaco. The most significant scientifically is the agreement to set up a study of, and consider a protocol on, air pollution over the Mediterranean. Air pollution will be "one of the biggest surprises in the future" Keckes believes. Much of the mercury and lead pollution arriving in the Mediterranean may travel first through the air, not water. And Keckes can now begin setting up some 10 to 15 new laboratories to monitor the air transport of pollutants. He expects results in 4 to 5 years. Another Monaco success for Keckes is his successful resistance of moves to make the pollution research reports secret. Keckes insisted they will be published; and they will be.

Keckes has ensured that governments approve their own research stations, so their results cannot be dismissed; and has insisted that the research be done by them rather than for them, to build up a national base for pollution monitoring. (UNEP has provided $\$ 1.7$ million for this purpose.) $\mathrm{He}$ has made sure that all results are intercalibrated, to be strictly comparable. And no doubt to the comfort of the least developed nations of the Mediterranean he also argues that for UNEP "protection of the environment is just one dimension of the development of the environment- for us protection for its own sake doesn't exist."

Robert Walgate 